\title{
EFFICACY OF INTRAVITREAL TRIAMCINOLONE ACETONIDE FOR DIABETIC MACULAR EDEMA
}

\author{
Prachand Gautam ${ }^{1}$, Koshal Shrestha ${ }^{2}$, Gyanendra Lamichhane ${ }^{3}$, Sushila Patel ${ }^{4}$
}

\begin{abstract}
INTRODUCTION: Diabetic retionopathy is a microangilpathy. The present study was done to investigate results of Intravitreal Triamcinolone Acetonide injection for the treatment diffuse diabetic macular edema.

MATERIAL AND METHODS: The study included 40 eyes of 40 patients with clinically significant diffuse diabetic macular edema. Eyes were diagnosed with diabetic macular edema according to Early Treatment Diabetic Retinopathy Study guidelines. An Intravitreal injection of Triamcinolone Acetonide at the dose of $4 \mathrm{mg} / 0.2 \mathrm{ml}$ was administered. Best corrected visual acuity was measured as the logarithm of the minimum angle of resolution (logMAR) and snellen vision drum and size of macular edema (hard exudates) was obtained by slit lamp biomicroscopy using +90 D Volk lens at each visit. Intraocular pressure (IOP) and other complications related with steroid and injection related complications were also evaluated. Subsequently patients were followed up on $1^{\text {st }}$ day, $2^{\text {nd }}$ week and $3^{\text {rd }}$ month.
\end{abstract}

RESULTS: All patients were completed second follow up at 3 months. The mean size of macular edema, which obtained at 3 months postoperatively, was significantly different from the baseline measurement from 1.4125 to 0.9474 DD. Mean visual acuity improved significantly from baseline at 3 months of follow up was $0.7421 \operatorname{LogMAR}(\approx 6 / 30 \mathrm{in}$ Snellen chart). Eleven eyes developed intraocular pressure higher than $21 \mathrm{mmHg}$ at $2^{\text {nd }}$ week postoperatively. Other drug and injection related complications were not developed. Increased IOP were controlled with anti glaucoma drugs.

CONCLUSIONS: Intravitreal Triamcinolone was a promising therapeutic method for diabetic macular edema. Triamcinolone Acetonide effectively reduces size of macular edema and improves visual acuity in the short term.

KEYWORDS: Diabetic Macular Edema; Disc Diameter; Intraocular Pressure; Intravitreal Triamcinolone Acetonide

1. Ophthalmologist, Glaucoma Specialist, Lumbini Eye Institute, Siddharthanagar, Bhairahawa, Nepal,

2. Ophthalmologist, Oculoplasty Specialist, Lumbini Eye Institute, Siddharthanagar, Bhairahawa, Nepal.

3. Ophthalmologist, Retina, Lumbini Eye Institute, Bhairahawa, Nepal

4. Ophthalmologist, Cornea Consultant, Lumbini Eye Institute, Siddharthanagar, Bhairahawa, Nepal

\author{
For Correspondence \\ Dr. Prachand Gautam \\ Ophthalmologist, Glaucoma Specialist \\ Lumbini Eye Institute, Siddharthanagar, \\ Bhairahawa, Nepal \\ E-mail:
}




\section{INTRODUCTION}

Diabetic retinopathy (DR) is a microangiopathy affecting the pre-arterioles, arterioles, capillaries and post-capillary venules, although large vessels may get involve. DR is the leading cause of blindness in patients aged 20-74 years. Blindness due to retinopathy is 25 times more common in the diabetic population. ${ }^{1-3}$ The diseases like diabetes and hypertension have become more common, leading to a greater prevalence of diabetic and hypertensive retinopathies in Nepal. Almost one fourth of the people aged 20 years and above and more than 10 percent of women in urban areas in Nepal showed diabetic tendency. ${ }^{4-5}$

Corticosteroids are effective in DR because of their ability to down regulate the production of vascular endothelial growth factors. ${ }^{2,6}$ The purpose of this study was to evaluate the efficacy and safety of IVTA injection for diabetic macular edema, using $+90 \mathrm{D}$ volk lens to evaluate the size of macular edema that is beneficial for those eye care centre where OCT not available.

\section{MATERIALAND METHODS}

This study was designed as a prospective, interventional, noncomparative case series. Place of the study was Lumbini Eye Institute. Forty eyes of 40 diabetic patients with clinically significant diffuse macular edema according to ETDRS guidelines were included. Baseline parameters were documented and included best corrected visual acuity (BCVA), measured as the logarithm of the minimum resolution log MAR and snellen vision drum, size of hard exudates (macular thickness) with volk +90D (vertical length of the disc $\mathrm{x}$ 1.3) and IOP with applanation tonometry. History of glaucoma, loss of vision due to other causes, eyes with very poor posterior segment visibility, patient previously treated with laser were excluded from the study. All of the patients were under good blood sugar control and median blood pressure $150 / 85 \mathrm{mmHg}$. All of them were informed about the procedure, and oral informed consent was obtained.

The Intravitreal injection of Triamcinolone was carried out under sterile conditions in the operation room. For topical anaesthesia, lidnocaine $4 \%$ eye drops were used and followed by application of povidine iodine, $4 \mathrm{mg} / 0.2 \mathrm{ml}$ with a 27 gauge needle and $1 \mathrm{ml}$ tuberculin syringe $3-3.5 \mathrm{~mm}$ posterior to the limbus at inferotemporal quadrant. After injection, the central retinal artery and vitreous cavity were examined by indirect ophthalmoscopy to monitor perfusion and vitreous haemorrhage. All patients were placed on topical antibiotics, four times daily, for 7 days after injections. The response to treatment was monitored by best corrected visual acuity using ETDRS charts, size of hard exudates and IOP at first post operative day ( $1^{\text {st }}$ POD), 2 weeks and 3 months. Other complications were recorded for analysis. Statistical analyses were performed with statistical software package (SPSS version 11) for Windows.

\section{RESULTS}

Out of the 40 patients, $22(55 \%)$ were male and $18(45 \%)$ were female. The mean age was $58.98 \pm 9.2$ years (range $40-88$ ). All eyes had clinically confirmed diffuse diabetic macular edema. No immediate complication from injection occurred.

Mean size of the macular edema, BCVA as logMAR (and with Snellen chart), and IOP assessed preoperatively and at $1^{\text {st }}$ day, 2 weeks, and 3 months postoperatively are shown in (table 1).

Table 1: Mean BCVA, IOP and Size of macular edema preoperatively and during the follow-ups

\begin{tabular}{|c|c|c|c|c|}
\hline \multirow[t]{2}{*}{ Parameters } & \multirow{2}{*}{$\begin{array}{l}\text { Preoperatively } \\
\text { (Baseline) }\end{array}$} & \multicolumn{3}{|c|}{ Follow-up period } \\
\hline & & $1^{\text {st }}$ post op day & 2 weeks & 3 months \\
\hline \multirow[t]{2}{*}{ BCVA (logMAR) } & $0.30-1.50$ & $0.30-1.50$ & $0.30-1.50$ & $0.20-1.30$ \\
\hline & $1.0 \pm .35$ & $1.0 \pm .35$ & $0.98 \pm .35$ & $0.74 \pm .33$ \\
\hline \multirow{2}{*}{$\begin{array}{l}\mathrm{IOP}(\mathrm{mmHg} \text { applanation }) \\
(\text { mean } \pm \text { SD) }\end{array}$} & $10-20$ & $10-40$ & $10-26$ & $12-30$ \\
\hline & $14.70 \pm 2.50$ & $18.73 \pm 5.98$ & $16.67 \pm 2.94$ & $16.42 \pm 3.35$ \\
\hline \multirow{2}{*}{$\begin{array}{l}\text { Size of Macular Edema (DD) } \\
\text { (mean } \pm \text { SD) }\end{array}$} & $0.50-2.00$ & $0.50-2.00$ & $0.50-2.00$ & $0.50-1.50$ \\
\hline & $1.41 \pm 0.49$ & $1.41 \pm 0.48$ & $1.41 \pm 0.49$ & $0.94 \pm 0.41$ \\
\hline
\end{tabular}

Mean baseline size of macular edema was $1.4125 \pm 0.492 \mathrm{DD}$ (range 0.50-2.00 DD). Mean size of macular edema was decreased in 3rd months from $1.4125 \pm 0.492 \mathrm{DD}$ to $0.9474 \pm$ 0.947 DD. However, size of macular edema had not changed significantly at the $1^{\text {st }}$ post operative day and 2 weeks follow up periods $(\mathrm{P}>0.05)$.(Fig.1 and 2$)$
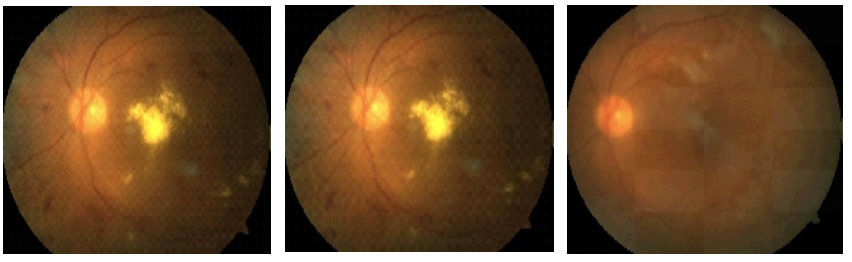

Figure 1 (A): Pre injection Fundus photo demonstrate macular edema, (B) Two weeks after injection, (C) At 3 months after injection demonstrates complete resolution of hard exudates. 


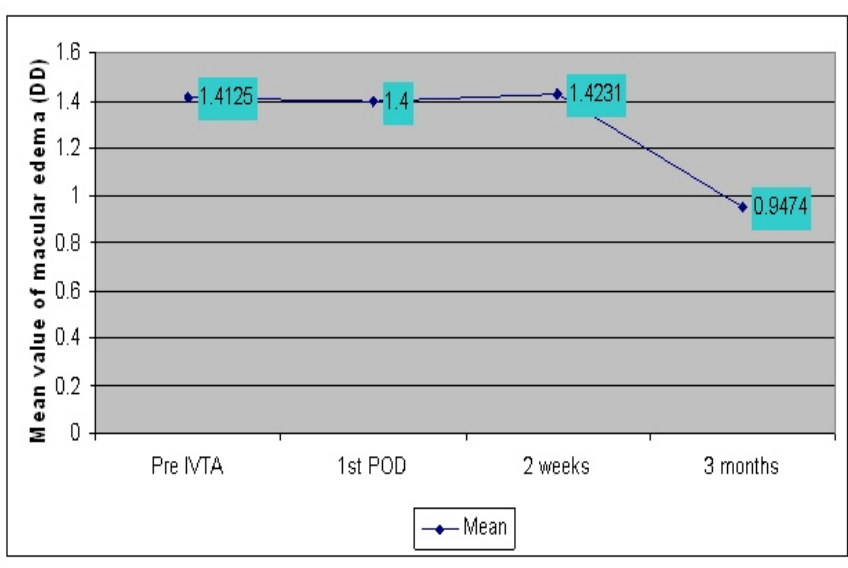

Figure 2: Time course of size of macular edema using +90D, showing a significant difference between preoperative and 3 months postoperative macular edema (in DD)

Mean BCVA as LogMAR had improved significantly from baseline at 3 months follow-up intervals $(\mathrm{P}<0.05)$ but there was no statistically significant difference at $1^{\text {st }}$ postoperative day and 2nd week after IVTA.

Same as logMAR, with Snellen chart, BCVA was improved 3 Snellen lines at 3 months postoperatively. However, visual acuity had not changed significantly $1^{\text {st }}$ post up day and 2 nd week after IVTA in Snellen chart (Fig. 3).

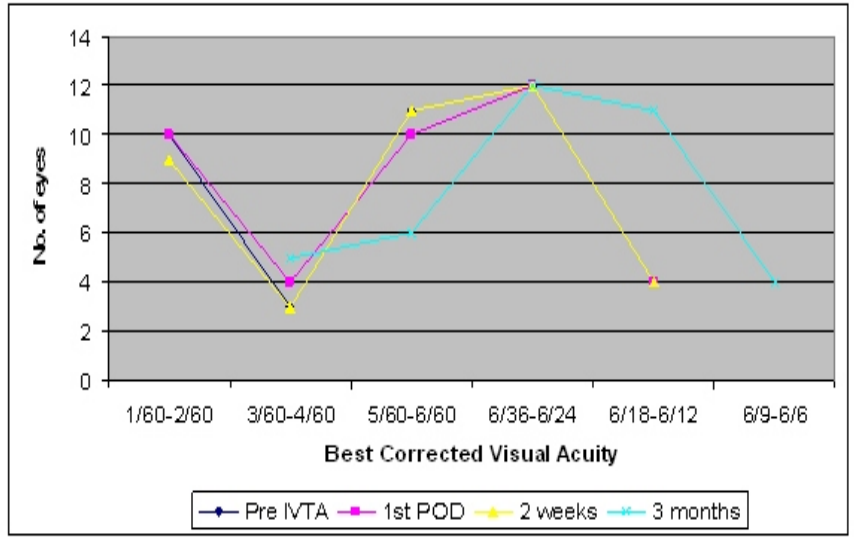

Figure 3: Time-course of Snellen visual acuity, showing a significant improvement only at 3 months after injection IOP had increased at $1^{\text {st }}$ post operative day more than 20 $\mathrm{mmHg}$ in 11 eyes $(27.5 \%)$, at 2 weeks in 2 eyes $(5 \%)$ IOP ranged from 26 to $30 \mathrm{mmHg}$ whereas only a single eye $2.5 \%$ had IOP ranged from 26 to $30 \mathrm{mmHg}$ at 3 months. However, there was no statistically significant difference between at 2 weeks and 3 months of follow-up (figure 4).

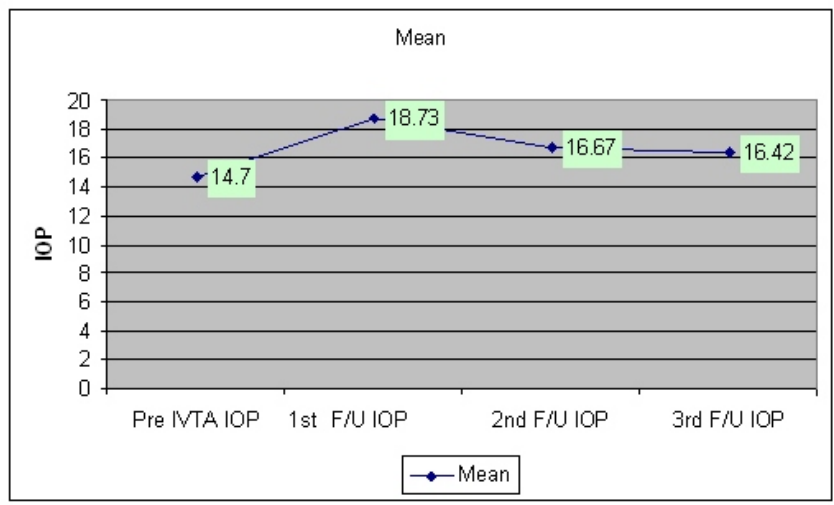

Figure 4: Time-course of IOP measurement, showing no significant difference between preoperative and postoperative values

During the follow-up eyes developed IOP values higher than $21 \mathrm{mmHg}$ were controlled by topical anti-glaucomatous treatment.

\section{DISCUSSION}

Approximately $10 \%$ of the diabetic population has type 1 (insulin-dependent) diabetes mellitus, which is usually diagnosed before the age of 30 years. The majority (90\%) of diabetic patients, however have type 2 (non-insulindependent) diabetes mellitus, which is diagnosed after the age of 30 years. Diabetic retinopathy is a highly specific vascular complication of both type 1 and type 2 diabetes mellitus, and the duration of diabetes is a significant risk factor for the development of retinopathy. ${ }^{1,7}$

Macular edema represents a common pathologic sequel of the retina associated with a broad spectrum of potential insults. Diabetic macular edema manifests as intraretinal and subretinal accumulation of fluid resulting from increased vascular permeability. Retinal vascular leakage may occur focally from microaneurysms or diffusely from a more generalized breakdown of the bloodretinal barrier. Although focal macular edema has been shown to be amenable to treatment with laser photocoagulation, diffuse macular edema has a poor prognosis with this treatment method. The exact pathogenesis of diffuse diabetic macular edema has not been elucidated, although a breakdown of the inner bloodretinal barrier is accepted. The possibility of an endogenous permeability factors released by ischemic retina has been suggested. One group of endogenous factors, prostaglandins, is known mediators of vascular permeability. Corticosteroids have long been used in the treatment of cystoid macular edema because of their ability to inhibit the arachidonic acid pathway, of which prostaglandins are a product. Corticosteroids may 
also down regulate the production of vascular endothelial growth factor, a known vascular permeability factor. Triamcinolone Acetonide, a corticosteroid suspension, has been shown experimentally to reduce breakdown of the bloodretinal barrier. Stabilization of The bloodretinal barrier introduces a rationale for corticosteroid treatment of diabetic macular edema. ${ }^{8}$

Martidis et al. evaluated the safety and effectiveness of Intravitreal injection of $4 \mathrm{mg}$ of Triamcinolone Acetonide in 16 eyes with clinically significant diabetic macular edema that had failed to respond to at least two sessions of laser photocoagulation. They found that central macular thickness, as measured by OCT, had decreased by $55 \%, 57 \%$, and $38 \%$ at the 1-month, 3-month, and 6-month follow-up intervals, respectively.

Another similar study by Taygan Yilmaz et al on 2008, efficacy via change in centre macular thickness was assessed, which is considered a strong prognostic measure of levels of DME. At 3-month $(\mathrm{P}<0.00001)$ and 6-month $(\mathrm{P}=0.04)$ of follow-up, there was a significant reduction in central macular thickness. However, there was no significant difference in central macular thickness values at 3 months and 6 months.

In our study, size of the macular edema was evaluated with slit lamp biomicroscopy using $+90 \mathrm{D}$ Volk lens. There were no other studies where the size of macular edema evaluated by using +90D Volk lens. In our study Mean size of macular edema was decreased in 3rd months from $1.4125 \pm 0.492 \mathrm{DD}$ to $0.9474 \pm 0.947 \mathrm{DD}$. However, size of macular edema had not changed significantly at the $1^{\text {st }}$ post operative day and 2 weeks follow up periods.

Jost B. Jonas et al., in their prospective study over a follow up period of six months compared BCVA; patients were randomly allocated in two groups undergoing IVTA. In study group who receive Intravitreal injection were 20 patients and in controlled group 16 patients who underwent macular grid laser coagulation. They found the BCVA at 3 months $(\mathrm{P}=0.01)$ and 6 months $(\mathrm{P}=0.02)$ were statistically similar. It is due to the Triamcinolone Acetonide crystals were resolved and completely disappeared out of the vitreous cavity 3 to approximately 6 months after the injection..$^{10}$

In our series, functional response at 3 months, with a significant improvement in visual acuity, was demonstrated. Lasseron et al. evaluated the correlation between improvement in visual acuity and the reduction of foveal thickness after a single Intravitreal injection and 3 months after the treatment. They could not demonstrate a relationship between them in the short-term either. ${ }^{11}$
The main side effect observed in previous studies was IOP elevation, which was reported in $20-80 \%$ of patients after Intravitreal Triamcinolone injection. ${ }^{9,12,13,14}$ It was reported that IOP started to increase approximately 2 weeks to 1 month after the injection, reached a plateau-like maximum approximately 1-8 months later, and returned to preoperative values 8 -9 months after injection. ${ }^{15}$ We observed IOP elevation in $27 \%$ of the eyes, at first postoperative day due to increased Intravitreal volume and $5 \%$ and $2.5 \%$ at 2 weeks and 3 month of follow-up subsequently. In our study, IOP values higher than $21 \mathrm{mmHg}$ were controlled by topical anti-glaucomatous treatment. Massin et al. tested all eyes with topical dexamethasone before Triamcinolone injection to detect susceptibility to corticosteroid-induced increase IOP. They thought that patients with glaucoma or history of corticosteroid-induced IOP elevation should not be given Intravitreal Triamcinolone.

In our study, we were not found any drug or injection related complication except increase IOP.

\section{CONCLUSIONS}

Intravitreal Triamcinolone was a promising therapeutic method for diabetic macular edema. Intravitreal injection of 4 $\mathrm{mg}$ of Triamcinolone Acetonide seems to be effective in improving diabetic macular edema and visual acuity in the short term. As the study was carried out in small number of patient, further study with large number of patient and longer period of follow- up is recommended to assess the long-term efficacy and safety. Although it does not have a permanent treatment effect, it may be a therapeutic option for poor socioeconomic condition patients and that do not respond to laser photocoagulation.

\section{ACKNOWLEDGEMENT}

The authors are indebted to Dr. Sanyam Bajimaya, Tilganga Institute of Ophthalmology for his help and support in carrying out the study. The authors are also grateful to Ms. Srijana Sharma Gautam for her help in doing the statistical analysis.

\section{REFERENCES}

1. Albert \& Jakobiec, Principles and Practice of Ophthalmology; 2nd edition, 2000; Pg. 1900-1914.

2. AP Ciardella J Klancnik, W. Schiff, G. Barile. Intravitreal Triamcinoloce for the Treatment of Refractory Diabetic Macular Oedema with Hard Exudates; BJO Vol. 88, No. 9, September 2004, Page 1131-1136. http://dx.doi.org/10.1136/ bjo. 


\subsection{PMid:15317702 PMCid:PMC1772301}

3. Shrestha S, Malla OK, Karki DB, Byanju RN. Retinopathy in a diabetic population, Kathmandu University Medical Journal (2007), Vol. 5, No. 2, Issue 18, 204-09.

4. L.-M. Chuang, S. T. Tsai, B. Y. Huang Ü and T. Y. Tai on behalf of the Diabcare-Asia 1998 Study Group, 2002 Diabetes UK. Diabetic Medicine, 19, P. 978-85.

http://dx.doi.org/10.1046/j.1464-5491.2002.00833.x PMid: 12647837

5. Shrestha $S$, Karki DB, Byanju R, Malla OK, Shrestha SM, Pradhananga CL . Visual outcome of laser treatment in diabetic retinopathy, Kathmandu University Medical Journal (2007), Vol. 5, No. 1, Issue 17, 72-80.

6. Adam Martidis MD, Jay S. Duker MD, Paul B. Greenberg MD. Intravitreal Triamcinolone for Refractory Macular Oedema, Ophthalmology, Vol. 109, Issue 5, May 2002, Pg. 920-27. http://dx.doi.org/10.1016/S0161-6420(02)00975-2

7. Klein R, Klein BE, Moss SE. The Wisconsin Epidemiologic Study of Diabetic Retinopathy, II: Prevalence and high risk of diabetic retinopathy when age at diagnosis is less than 30 years, Arch Ophthalmol 1984; 102:520-6

http://dx.doi.org/10.1001/archopht.1984.01040030398010 http://dx.doi.org/10.1001/archopht.1984.01040030405011 PMid:6367724

8. Vasumathy Vedantham, Ramasamy Kim. Intravitreal injection of triamcinolone acetonide for diabetic macular edema: principles and practice, IJO 2006;54(2): 133-137

http://dx.doi.org/10.4103/0301-4738.25840

9. Martidis A, Duker JS, Greenberg PB. Intravitreal triamcinolone for refractory diabetic macular edema, Ophthalmology 2002; 109(5):920-27

http://dx.doi.org/10.1016/S0161-6420(02)00975-2

10. Myron Ynoff, J.S.Duker, editors. Ophthalmology, 2nd edition, 2006; pg.877-86

11. Larsson J, Zhu M, Sutter F, Gillies MC. Relation between reduction of foveal thickness and visual acuity in diabetic macular edema treated with intravitreal triamcinolone.

Am J Ophthalmol, 2005; 139:802-06.

http://dx.doi.org/10.1016/j.ajo.2004.12.054

PMid:15860283

12. Ip MS, Kumar KS. Intravitreal triamcinolone acetonide as a treatment for macular edema from central retinal vein occlusion, Arch ophthalmol, 2002; 120:1217-19.

13. Jonas JB, Ingrid Kreissig, MD; Antje Sofker, MD; Robert F, Degenring, MD. Intravitreal injection of triamcinolone for diffuse macular edema, Arch Ophthalmol, 2003; 121: 57-61. http://dx.doi.org/10.1001/archopht.121.1.57 PMid:12523885

14. Jonas JB, Kreissig I, Degenring RF. Intraocular pressure after intravitreal injection of triamcilonone acetonide, $\mathrm{Br} J$ Ophthalmol, 2003;87:24-27.

http://dx.doi.org/10.1136/bjo.87.1.24

15. Jonas JB, Degengring $R F$, Kamppeter BA, Kreissig I, Akkoyun I. Duration of the effect of intravitreal triamcinolone acetonide as treatment of diffuse diabetic macular edema., Am $J$ ophthalmol, 2004; 138:158-60 http://dx.doi.org/10.1016/j.ajo.2004.02.025 http://dx.doi.org/10.1016/j.ajo.2004.07.007 